\title{
O documentário institucional de divulgação científica: a representação cinematográfica do Instituto Butantan
}

Priscila de Almeida Xavier

\section{Resumo:}

O artigo pretende pensar a relação que se faz entre Cinema e História, partindo de uma discussão dos tipos de análise que podem ser ponderadas para o campo do cinema documentário. Considerando também a questão dos gêneros institucional, científico e didático, a partir da representação que uma instituição de pesquisa científica faz de si, através do cinema. Para tal, propõe-se um exame do filme "La mort qui guette" (Bélgica, 1952), pertencente ao arquivo permanente do Instituto Butantan, depositado na Cinemateca Brasileira, para fins de conservação.

\section{Palavras Chave:}

História; Instituto Butantan; Filme científico; Filme institucional; Preservação

\begin{abstract}
:
The article intends to look over the relationship between Cinema and History. It starts by discussing possible kinds of analysis to the field of documentary cinema. It ponders as well about the matter of gender, institutional, scientific or didactic according to the representation a scientific research institution makes of itself through cinema. To such intent, it examines the movie "La mort qui guette" (Belgium, 1952), part of to the permanent archives of Butantan Institute and guarded by the Brazilian Cinemateca for conservation.
\end{abstract}

\section{Keywords:}

History, Butantan Institute, Scientific movies, Institutional movies, Preservation

"Film is about something, whereas reality is not"(1)

\section{Dai Vaughan}

Uma análise fílmica requer o conhecimento de alguns tipos de análise, para então entrar na abordagem do filme em si. A que se pretende aqui procura entender o filme como um elemento social em sua construção, dentro de um certo contexto histórico determinado, tomando, porém, como ponto de partida um exame dos elementos audiovisuais que compõem a obra para, então, seguir para um olhar mais externo.

O presente artigo é parte do que vem sendo desenvolvido na pesquisa de Mestrado que, por sua vez, tem por objetivo discutir a representação cinematográfica do Instituto Butantan em um determinado período histórico, a saber, entre os anos 1928-1945, que correspondem à direção de Afrânio Peixoto, que sucedeu Vital Brazil, primeiro diretor e figura emblemática para a instituição. Essa representação é tomada através de filmes selecionados a partir de seu próprio acervo do arquivo de filmes em películas do Butantan, que está em depósito na Cinemateca Brasileira (2). 
Mesmo sendo o Instituto Butantan uma instituição muito reconhecida por seu trabalho no âmbito da pesquisa em área de ciências biomédicas, seu arquivo permanente é ainda pouco explorado por estudiosos. Há, portanto, toda uma documentação a respeito dessa história institucional que foi insuficientemente debatida.

Aqui, no caso, procuro discutir a representação cinematográfica da instituição através de uma proposta de análise de um dos filmes desse arquivo (3), que coloca o próprio Butantan como tema. O filme que será apresentado chama-se "La mort qui guette" (título em francês, que foi traduzido como "A morte que espreita"), uma produção de curta-metragem belga de 1952, com aproximadamente 22 minutos de duração.

O filme em questão não faz parte dos que foram selecionados até o momento para a análise final da dissertação de Mestrado, pois não está dentro do recorte estabelecido para a seleção, entre os quais: não foi produzido no Brasil e não está dentro do período delimitado, a lembrar de 1928 a 1945 . A escolha de tal filme, assim sendo, se justifica pela estrutura de sua narrativa, que foi verificada através da decupagem planoa-plano. Este pode ser percebido no campo da não-ficção, dentro do gênero científico, isto significa que, almeja levar ao cinema a precisão dos dados de uma pesquisa científica para os leigos no assunto. Dentre a documentação extra-filme localizada até o momento no arquivo permanente do Instituto Butantan a respeito do filme escolhido, temos uma carta de 1951 com um pedido oficial de autorização de filmagem da equipe belga, que pretendia fazer um filme sobre o Butantan (4).

Outro dado que justifica essa escolha, no conjunto de filmes de arquivo a que pertence, é o fato de estar em bom estado de conservação (5). Esse é uma questão que não é comumente dimensionada nas análises fílmicas. É fundamental lembrar que um bom estado físico-químico do suporte permite a verificação e mesmo a telecinagem (resumindo: migração de um suporte a outro), nesse caso específico, do acetato de celulose para o DVD (6), o que confere uma maior durabilidade ao suporte original, uma vez que será menos manipulado, garantindo assim a permanência da informação audiovisual por um período maior de tempo.

\section{Alguns pontos de vista sobre a análise fílmica}

Ter como objeto a análise de um filme é pensar sua relação com o meio social e o contexto histórico a que é submetido. Afinal, há um discurso na linguagem que dialoga com seu contexto, na construção de uma visão, consciente ou não, do realizador, que tem seu meio como influência e/ ou interferência em sua obra.

No caso de uma relação entre o Cinema e a História, que é justamente um dos aspectos centrais do que venho desenvolvendo na pesquisa de Mestrado, um pesquisador que trabalha nesse sentido e que não pode passar desapercebido é Marc Ferro que, em seu ensaio "O filme: uma contra-análise da sociedade" (7)fala sobre a dicotomia entre a análise do conteúdo do filme e o que pode ser extraído deste, para pensar seu contexto de produção. Ferro vê o cinema como algo que está fora da esfera da História, independente do poder, assim sendo, sua contra-história. Pensando a crítica a esse ensaio, Eduardo Morettin (8) fala do caráter polissêmico da imagem e não da separação entre o conteúdo ideológico-estético do filme versus seu contexto históricosocial, conforme o pensamento de Ferro.

Para uma análise sociológica, o filme também é visto como parte do imaginário social, como uma dimensão do processo social, não apenas um reflexo deste. Já que todo filme tem sua narrativa, a história que quer contar, o que se coloca como pertinente é o que Pierre Sorlin trata em seu texto "Filme e ideologia"(9): o filme se constrói como um ato social, sua narrativa é apenas uma parte dessa construção, que pressupõe uma seleção, redistribuição, re-tradução e reorganização de uma certa realidade, não é nunca uma duplicação da mesma. Para selecionar os filmes de uma pesquisa, Sorlin utiliza os seguintes critérios: (10)

- trabalhar com filmes conhecidos, uma produção que foi muito vista no período de seu lançamento (número 
de ingressos vendidos)

- sucesso de crítica, que coloca valores em cheque, foge de modismos (há filmes que fazem sucesso de público, mas que se esgotam rápido).

Dessas duas questões tem-se o exame de poucos filmes, não é para pensar na quantidade, mas sim na qualidade da análise, levantar problemas sociológicos que se repetem, a partir de questões relevantes. Lembrando que será analisado aqui apenas um filme.

O filme a ser examinado não se encaixa nessas categorias de uma análise sociológica como propôs Sorlin. É um filme que não foi visto por um grande público, não foi para o circuito comercial de cinema, portanto, não há como medir sua venda de ingressos, se não é esse o objetivo final da produção. Também não há documentação encontrada a respeito de sucesso de crítica, uma vez colocada tal especificidade de produção. Provavelmente os espectadores deste eram freqüentadores do próprio Instituto Butantan (em exibições internas) ou mesmo de promoção institucional externa (mostrado em congressos, eventos e mesmo em salas de aula); sendo uma produção estrangeira, possivelmente sua exibição seria direcionada a leigos aos trabalhos do Instituto. A análise, conseqüentemente, não pode se restringir ao ponto de vista da Sociologia, o aspecto histórico é primordial aqui, o que é próprio da linguagem cinematográfica dá elementos para compreender o momento histórico a que o realizador está inserido.

A relação entre realizador e público é sempre desigual, segundo Macdougall (11) a realização do filme não se faz de uma idéia isolada, o diretor faz parte da sociedade e sempre se relaciona com o espectador, mesmo que de formas divergentes, sua relação com o filme é de perda, já o espectador ganha sempre, está na expectativa. Para Jay Ruby, a construção de um filme implica uma cadeia: produtor - processo - produto, isso significa que o filme é o resultado de uma concepção da sociedade, que resulta em um produto, mas o que se deve levar em conta é que na relação com o público, muitas vezes este último não percebe essa cadeia e toma o filme como dado de realidade (12).

Para me aprofundar no filme, no que diz respeito à sua estética, é preciso introduzir uma outra discussão: todo filme é uma construção, conforme já explicitado, mesmo os filmes documentais são feitos a partir de escolhas do diretor. O realizador faz as escolhas a partir do que pretende passar ao espectador, a linguagem cinematográfica se justifica a partir dessas escolhas, para mostrar que um filme não é a reprodução do real simplesmente, há que se pensar os atributos da linguagem cinematográfica. A relação entre realidade e o que é filmado não é tão simples, muito já se discutiu, até mesmo se o filme documental seria uma representação, reprodução ou mesmo duplo do real, como debatido por Sorlin.

Já Roger Odin coloca uma outra opção analítica nas relações entre público e realizador, estabelecendo uma ponte com as interpretações lingüísticas. Em "Film documentaire. Lecture documentarisante"(13) trata da leitura que o espectador faz do filme, que pode ser para o viés fictivisante ou documentarisante, a leitura do filme se faz externo a ele, é pragmática. Na chave do fictivisante, o que se coloca é a "recusa da construção pelo leitor de um eu de origem", ou seja, não problematiza o fato de haver um enunciador, sendo ele dos pressupostos do que seria a ficção ou realidade. Já no caso da leitura documentarisante, o que se coloca é a "construção pelo leitor de um enunciador pressuposto real", seja ele, a câmera, o diretor, a sociedade, o responsável pelo discurso, enfim (14). O filme é um documento dessa realidade lida pelo espectador. Partindo daí, tem-se que o espectador, leitor do filme, entra numa relação com este que, por sua vez, também faz suas instruções do tipo fictivisante ou documentarisante; cabe ao leitor aceitar ou recusar o eixo dado. Deste modo, essas oposições entre documentário e ficção, realidade e mentira são muito mais complexas de serem aferidas na perspectiva da interpretação de um filme. 


\section{A tecnologia vence a natureza: La mort qui guette (1952)(15)}

Nas cartelas de apresentação já há uma busca de legitimidade científica, através dos nomes oficiais que patrocinaram a realização do filme: "Royaume de Belgique - Ministere de l'instruction publique/ Service cinématographique"/ Production: "Belgian World Pictures"/ "Nous exprimons notre gratitude eu Département de l'Hygiène et de la Santé Publique de l'Etat de São Paulo-Brésil qui permit la réalisation de ce film avec la collaboration de l'Institut Butantan”.

A música dá uma sensação de suspense, enquanto vêem-se os créditos iniciais, gerando expectativa, o que é corroborado pelo título do filme "A morte que espreita". O espectador pode esperar por um filme de suspense ou um filme de ciências, se a imagem da cartela inicial for lida com o som. A imagem que se segue está em P\&B, há um grito e uma serpente aparece sendo atropelada. A trilha muda, fica suave. Entra a sequiência de apresentação do Butantan.

Começa a voz do narrador "voz over", justamente enfatizando as horas, detalhe do relógio em close que marca o início desse atendimento (3 horas), pois o tempo é fundamental no procedimento após a picada, conforme informa o narrador. O próximo plano que se segue começa com um plano fechado de uma rua, onde se ouve o som de uma sirene e logo em seguida uma ambulância entra no campo de visão, a câmera a acompanha pelas ruas da cidade, afastando-se para abrir, sem corte, para um plano geral, revelando o centro da cidade de São Paulo, com seus prédios e carros, até a ambulância desaparecer do plano - aqui a narração fala do surgimento do Instituto, não da cidade que as imagens mostram. Corte para o plano geral de um prédio do Instituto Butantan, que mais parece uma fazenda no interior do que uma construção da cidade que o plano anterior acabou de mostrar. A ambulância, que seria a mesma mostrada no centro de São Paulo, chega ao hospital. O paciente é tirado da ambulância e o filme que até então era P\&B fica colorido. O recurso utilizado para demarcar o fim dessa apresentação geral, para a produção específica do Butantan é justamente a mudança da cromia: o que era P\&B passa a ser colorido, entramos de vez no Butantan, por isso, a questão da cor é fundamental no filme, vale ressaltar.

Há uma dramatização da sequiência subseqüente. Começa a narrativa sobre a produção de soros antipeçonhentos (16) - do fim do seu ciclo (a aplicação no paciente), passando por todo seu processo e a tecnologia demandada para tal. A narração passa a nos explicar os procedimentos do Butantan, no caso quando o soro chega à vítima, o que é mostrado é o rosto de uma criança picada, sob o efeito do soro,com a câmera parada se fechando até o close. Há uma grande quantidade de planos, o que aproxima o espectador da dor desse paciente, que para "piorar" é uma criança, que dá mais apelo à narrativa, comove ao espectador. Assim, o filme, apesar de se inserir no campo do chamado documentário, recorre às estratégias ficcionais a fim de promover o envolvimento do público.

A filmagem é realizada com primeiros planos e closes, sendo a maior parte dos planos do tipo americano. O corte de montagem se coloca com alguns fade in/ out e com cortes secos, dentro daquilo que Bazin denominou montagem invisível: a mudança de planos é feita de forma a que o espectador não tenha surpresas, sugerindo neutralidade. Como é sabido, nenhuma ação realizada na montagem de um filme é neutra, dado que há escolha do diretor ou montador, que tenta imprimir seu ritmo ao tempo da duração da ação.

O tema central do filme é a produção de soros antipeçonhentos, a maior parte do tempo da narrativa é dedicada à produção de soros antiofídicos. "La mort qui guette" tem sua narrativa estruturada em três partes principais: uma introdução, que é a apresentação do Instituto Butantan (até o momento em que passa do P\&B para o colorido); seguida por outra preenchida pelo desenvolvimento da temática: produção de soros antipeçonhentos; e, por fim, a conclusão, que fala da tecnologia e relevância do Instituto Butantan. Essas três partes podem ser divididas em dez seqüências norteadoras da narrativa, sendo: prólogo (pequena dramatização); a apresentação do Instituto Butantan; a finalidade do soro antipeçonhento (atendimento de 
paciente picado por cobra); turismo (sequiência curta); manuseio de ofídios; produção de soro antiaracnídeo; produção de soro antiescorpinídeo; produção de soro antiofídico (maior seqüência, com mais de 8 minutos); tecnologia aplicada ao desenvolvimento da ciência e conclusão (trecho muito comprometido em seu estado de conservação, devido a isso não será analisado).

O filme segue com uma pequena seqüência que apresenta o Butantan como lugar de lazer para a população, a narração convida o espectador à visita, enquanto são mostradas imagens de locais do Instituto, como o serpentário, por exemplo. A sequiência a seguir é o central da narrativa, com a descrição do processo de produção dos soros antipeçonhentos do Instituto, sempre com a presença desse narrador que nos conduz e que, muitas vezes, discursa sobre dados que não são visualizados. Não há entrevistas, nem nomeação das personagens (funcionários, pacientes, freqüentadores do Butantan etc). No plano seguinte, o narrador continua conduzindo a história, nomeia as espécies brasileiras de serpentes, mas o que pode ser visto nas imagens, em plano geral, são várias serpentes soltas no serpentário, sem a identificação de nenhuma, ou seja, há aqui a condução do olhar pela voz.

A trilha não foi composta para a obra, conforme letreiros finais; é uma música instrumental orquestrada (cordas e sopros), continua no mesmo tom em quase todo o filme (com três exceções pontuais), como se fosse um som ambiente, não participa diretamente da narrativa enquanto condutor de sentimentos, como ocorre no prólogo, conforme já citado. Os momentos em que a trilha pode ser percebida, além de um som ambiente são: a sirene da ambulância que sai da cidade e entra no Butantan; a música que fica densa quando a imagem apresenta o jacaré, que pela imagem parece não oferecer perigo algum, daí a imagem atua contra a trilha; a extração de venenos da aranha e escorpião, com o "bip" do aparelho de choques, som reforçado pela imagem do próprio aparelho e por fim, o único diálogo explícito entre trilha e imagem, quando há o close das aranhas guardadas no laboratório, onde a música fica mais grave ao som de trompete, conforme a câmera se move e apresenta-nos cada nova espécie de aranha, dando a sensação de suspense.

A narração é constante, no sentido de sempre explicar o que se passa, porém, há momentos de silêncio, em que o espectador é levado a prestar atenção no que está sendo mostrado pela imagem, daí a fala cessa.

Continuando, há a extração do veneno das aranhas e escorpiões em laboratório, respectivamente, para a produção do soro antiaracnídeo e antiescorpinídeo. O narrador reforça a idéia de que a manipulação desses animais deve ser feita por profissionais, já que representa muito perigo, o que pode ser interpretado como um filme voltado ao público leigo. A sequiência dessa segunda parte do filme é finalizada com o processo de extração de veneno e produção do soro antiofídico, que ocupa a maior parte do filme, com quase 8 minutos de duração. Todo o processo de produção do soro é dado de forma didática, passo-a-passo, com números e informações químicas da produção.

Essa seqüência apresentada é fundamental para a narrativa fílmica. Nela há a produção de soros antipeçonhentos e a tecnologia utilizada para tal intento, porém, não se vê outras atividades desenvolvidas pelo Instituto como, por exemplo, a produção de vacinas, que já eram desenvolvidas no período da filmagem. A imagem que se vende até hoje do Butantan é do instituto ligado à produção de soros antipeçonhentos e, principalmente, do local onde se lida com cobras, permitindo a identificação plena entre Butantan e cobras.

Algumas dessas escolhas podem ser justificadas pela própria narrativa e pelo contexto de produção: o foco é o trabalho de produção, não quem a faz efetivamente, não há nomeação das personagens, os funcionários que aparecem não são o centro das atenções, não se apresentam, nem olham ou conversam com a câmera, não cedem entrevistas, apenas desempenham seu trabalho, que é o central - o foco está na instituição, não nos seus profissionais; hoje, a maior parte dos documentários teria entrevistas com especialistas e seu trabalho em uma instituição como essa. Um olhar possível que essa pequena análise aponta é que tipo de representação o Instituto Butantan faz de si e como quer ser visto pela sociedade externa, como responsável pela produção de 
soros antipeçonhentos e principalmente de soros antiofídicos.

A sequiência que antecede o final tem como tema a tecnologia aplicada aos trabalhos do Instituto. Começa com um plano aberto da fachada do chamado "prédio novo" (edifício inaugurado em 1940, para abrigar laboratórios de pesquisa, ficou conhecido dessa maneira pelos funcionários - um dado extrafílmico retirado de pesquisa com a documentação do Instituto). Depois há um plano médio de uma funcionária, que analisa espécime em formol e a prepara para ser verificada a seguir no microscópio eletrônico (que era considerado o mais moderno e preciso aparelho desse tipo naquele contexto). O Narrador exalta a máquina e seu uso e a tecnologia é venerada, com uso de planos mais longos e detalhados, diferentes dos apresentados no início da história. O microscópio passa a ser a personagem central aqui. Ainda falando em exaltação da tecnologia aplicada à ciência, o filme termina com uma conclusão acerca dos avanços e benefícios do Instituto Butantan, para a sociedade brasileira, aparentemente são mostradas imagens que já foram vistas anteriormente.

Nas classificações de gênero dentro do campo do documentário, esse filme seria considerado como um institucional científico, usado para fins didáticos e com um público específico. Normalmente, poderia ter sua análise reduzida à questão do gênero (institucional, científico, didático etc) e ter sua interpretação voltada apenas para os assuntos superficiais, daí, a análise se esgotaria de forma rápida. "La mort..." seria considerado na visão de Bill Nichols como expositivo (17). Em seus textos, o autor trata da classificação de gêneros de documentários. Em Representing reality (NICHOLS, 1991) fala de quatro gêneros e já no Introduction to documentary (NICHOLS, 2001) já são seis, lembrando que há um espaço temporal de mais ou menos vinte anos entre os dois livros. O que caracteriza um filme expositivo, segundo o autor, é a presença da voz over do narrador, que nunca aparece em cena e, geralmente, é masculina e fala em tom neutro. Pela decupagem de "La mort qui guette" temos esses elementos: o narrador é masculino e na maior parte do tempo seu tom tenta passar neutralidade. Nichols o chamaria de "voz de Deus" por nos explicar o que vemos na imagem, como na passagem em que vemos a produção de soros antipeçonhentos. Nela é a voz que comanda as imagens, com precisão de dados científicos e números que legitimam a ciência no filme, o espectador não precisa pensar no que vê, pois tudo já está dito.

Enfim, a escolha da montagem aqui é pela transparência, a mudança de planos ocorre normalmente pelo recurso do fade-in e fade-out, principalmente quando há mudança de sequiências, ao mudar de assunto, a idéia é fazer o espectador não perceber essa alteração. Há um objetivo com essa montagem pela transparência, o filme pretende passar uma informação com vigor científico, logo, precisa de uma linguagem seca, objetiva, daí também a mudança constante de planos, que se sucedem de forma rápida, durando em média de 10 a 15 segundos, sendo que foi percebido que há a média de 6 planos por minutos, ou seja, vêem-se muitas informações em pouco tempo.

Uma imagem no cinema nunca tem sentido em si mesma, seu sentido é construído pelas imagens que a precedem e sucedem. $\mathrm{O}$ som toma sentido à medida que seu ritmo é dado pela montagem, que é diferente da imagem, a linguagem do som leva em conta a fala e os silêncios que se intercalam, dando ritmo ao filme, sem contar a música, que ajuda a contar a história, não pode se justapor à cena.

Outra questão a ser colocada a partir de Sorlin e de Marc Ferro é sobre o visível no filme. Ambos autores falam dessa questão, o primeiro pensando o filme na chave da Sociologia e o último a partir da História, porém, nos dois casos temos a noção da dicotomia entre o visível e o não-visível. Para Sorlin, o visível pode dar a impressão de realidade, mesmo o filme sendo uma construção, há as escolhas do que o cineasta quer mostrar. Já o não-visível, vale lembrar, não é aquilo que não existe, não é invisível, sua compreensão está na chave da ausência, está presente, mas não é mostrado por uma série de questões, que devem ser colocadas no momento da análise do pesquisador. Para Ferro, há uma realidade latente por trás da aparente no filme, mesmo que isso apareça sem que o realizador o queira, o não-visível através do visível (18). Morettin apresenta a contradição desse não-visível mostrado no visível da imagem fílmica, isso simplificaria a questão, 
o filme enquanto obra cinematográfica pode ser visto de forma polissêmica, conforme já dito, não somente com "dois níveis de significados independentes" (19), pode trazer leituras opostas em sua construção, que faz pensar o período em que foram realizadas.

Finalizando, essa apreciação remete à questão do tempo e do espaço fílmico e de sua relação com a realidade. No texto de Walter Benjamin "A imagem de Proust"(20), o autor se debruça sobre a busca de Proust pela compreensão do mundo, que seria pelo método da consciência, não da reflexão. A analogia que pode ser tomada aqui é o fato deste filme ser considerado uma representação da realidade, através de suposta cientificidade. Não há certeza da realidade em Proust, o que lembramos não é o que foi vivido, mas sim uma reminiscência, com buracos desse vivido. A memória de quem viveu é infinita, não no sentido do eterno, mas do sem limites, o vivido mesmo tem fim.

Qual o sentido disso em um filme que seria a representação dessa realidade, que já é interpretada e rememorada? Os sentidos que estão em Proust não se dão pelo vivido, mas por sua rememoração, que é a trama que tece esse vivido, que busca o profundo da semelhança, que, por sua vez, não é representação ou reprodução apenas, é a imagem de ser vários. Para Benjamin, o tempo na obra de Proust, assim como pode ser visto no cinema, não é infinito, mas sim entrecruzado, como as tramas de um tecido. É por esse viés que pode ser compreendido um filme que mostra a ciência trabalhada por um Instituto, que se coloca como tema para seu espectador, o interlocutor que o reconhece. O filme não mostra a ciência como ela é feita na suposta realidade extracampo, mas ele coloca seu espectador diante de um objeto que, no caso, é a ciência sob a interpretação da linguagem fílmica.

A grande questão que o filme deixa ao seu espectador da década de 1950, no contexto do pós-guerra, é como a tecnologia pode passar por cima da natureza, como o homem pode dominar o mundo, através do conhecimento. Afinal, voltamos ao prólogo do filme, em que a imagem da serpente sendo atropelada por um carro, símbolo da vida moderna, se torna paradigmática nesse sentido.

\section{Bibliografia:}

BAZIN, André. <>. São Paulo: Brasiliense, 1985.

BENJAMIN, Walter. “A imagem de Proust”. In: . <> - volume I. São Paulo: Brasiliense, 1996.

CHION, Michel. <>. Paris: Armand Colin, 2004.

FERRO, Marc. "O filme: uma contra-análise da sociedade”. In: <>. São Paulo: Paz e Terra, 1992.

MACDOUGALL, David. <>. New Jersey: Princeton University, 1998.

MORETTIN, Eduardo Victorio. "Dimensões históricas do documentário brasileiro no período silencioso". In: <>. v.25, n.49. São Paulo jan./jun., 2005.

"O cinema como fonte histórica na obra de Marc Ferro". In: CAPELATO, Maria Helena Rolim. [et al.]. <>. São Paulo: Alameda, 2007.

NICHOLS, Bill. 〈>. Bloomington: Indiana University, 1991. 
. >> Bloomington: Indiana University, 2001.

ODIN, Roger. "Film documentaire. Lecture documentarisante". In: ODIN, R. e LYANT, J.C. (ed.). <>. Saint Etienne: Université de Saint-Etienne, 1984.

RUBY, Jay. "The image mirrored: reflexivity and the documentary film.” In: ROSENTHAL, Alan (ed.). <>. Berkeley: University of California, 1988.

SORLIN, Pierre. <>. Paris: Aubier, 1982.

\section{Notas:}

(1) Citação de Vaughan (1985: 710) em texto de Macdougall. In: MACDOUGALL, David. <>. New Jersey: Princeton University Press, 1998. Pág.41.

(2)O acervo em películas do Instituto Butantan, encontra-se em depósito na Cinemateca Brasileira, desde agosto de 2007, para melhor tratamento arquivístico e de preservação.

(3) Sobre essa questão do filme de arquivo, venho desenvolvendo um estudo em minha monografia do curso de Especialização em Organização de Arquivos, pelo IEB-USP.

(4)Nesse momento da pesquisa, ainda não foram encontrados outros documentos a serem comparados para afirmar com precisão a data e o motivo que levou uma equipe belga a filmar uma instituição científica brasileira naquele período.

(5) Dimensiono a questão da preservação do suporte, pela interferência que isso causa em uma análise mais atenta às questões estéticas próprias da linguagem cinematográfica, como a fotografia (iluminação e cromia do filme), o som (voz, trilha sonora), entre outros. Desenvolvi um trabalho de revisão de filmes no Setor de Preservação da Cinemateca Brasileira, onde lidei diretamente com a conservação física das películas, o que me permitiu ter esse olhar mais aprofundado nessa questão.

(6) A versão aqui analisada é uma cópia em DVD, que foi feita a partir de um original em película $16 \mathrm{~mm}$, com suporte em acetato de celulose, cuja restauração não foi realizada. Há trechos comprometidos tanto na imagem, quanto no som. O som é o mais atingido pelo desgaste do suporte, há trechos inaudíveis da narração, portanto, não é possível verificar a totalidade do texto oral em francês. A parte final do filme está totalmente comprometida, não sendo possível o exame deste trecho.

(7) FERRO, Marc. “O filme: uma contra-análise da sociedade”. In: 〈>. São Paulo: Paz e Terra, 1992. Págs. 79-115.

(8) MORETTIN, Eduardo Victorio. “O cinema como fonte histórica na obra de Marc Ferro”.In: 〈>. Ano 20. n³8 Jan-Jun 2003. Págs. 15-16.

(9) SORLIN, Pierre. 〈>. Paris: Aubier, 1982. Págs. 199-242.

(10) Em sua pesquisa, Sorlin analisou filmes italianos da década de 1950, considerados do gênero da ficção.

(11) MACDOUGALL, David. <>. New Jersey: Princeton University, 1998. Págs.40-41. 
(12) RUBY, Jay. "The image mirrored: reflexivity and the documentary film." In: ROSENTHAL, Alan (ed.). <>. Berkeley: University of California, 1988. Págs. 64-77.

(13) ODIN, Roger. "Film documentaire. Lecture documentarisante". In: ODIN, R. e LYANT, J.C. (ed.). «>. Saint Etienne: Université de Saint-Etienne, 1984.

(14) Idem. Ibidem. Págs. 268-269.

(15) A análise apresentada aqui não será um exame plano-a-plano.do filme, pretendo abordar os principais pontos da narrativa, para uma possível compreensão da estrutura do filme.

(16) Soros utilizados em pacientes que foram vítimas de animais peçonhentos, como serpentes, escorpiões e aranhas. No caso, o Instituto Butantan produz soros antiofídicos (contra o veneno de cobras), o antiescorpinídeo (contra o veneno de escorpião) e o antiaracnídeo (contra o veneno de aranhas). Hoje, cada vez mais a produção de soros torna-se mais específica, sendo desenvolvido um tipo de soro para cada espécie de animais como, por exemplo, há um soro específico para picadas de corais, outra para cascavéis etc.

(20) NICHOLS, Bill. Representing reality - issues and concepts in documentary. Bloomington: Indiana University, 1991.

Introduction to documentary. Bloomington: Indiana University, 2001.

(21)FERRO, Marc. "O filme: uma contra-análise da sociedade". In: Cinema e História. São Paulo: Paz e Terra, 1992. Pág.88.

(22) MORETTIN, Eduardo Victorio. "O cinema como fonte histórica na obra de Marc Ferro". In: CAPELATO, Maria Helena Rolim... [et al.]. História e Cinema. São Paulo: Alameda, 2007. Pág.42.

(23) BENJAMIN, Walter. "A imagem de Proust". In: Magia e técnica, arte e política. Obras escolhidas - volume I. São Paulo: Brasiliense, 1996. Págs.36-49.

\section{Mini Currículo :}

Graduada em História (bacharelado e licenciatura) na FFLCH-USP. Atualmente é mestranda em Ciências da Comunicação pela ECA-USP, com bolsa FAPESP e é estudante de Especialização em Organização de Arquivos pelo IEB-USP. 